\title{
VIABILIDADE ECONÔMICA DA PRODUÇÃO FAMILIAR DE ALIMENTOS PARA OS MERCADOS INSTITUCIONAIS DE ALEGRE-ES
}

\author{
Caio César Soares Biancardi ${ }^{1}$ \\ Rafael Rodrigues ${ }^{2}$ \\ Haloysio Mechelli de Siqueira ${ }^{3}$ \\ Joana Junqueira Carneiro ${ }^{4}$ \\ Maria Aparecida Fernandes ${ }^{5}$
}

\section{RESUMO}

Este artigo apresenta e discute os resultados da análise de viabilidade econômica da produção familiar de alimentos, inserida na feira livre e nos mercados institucionais (Programa de Aquisição de Alimentos - PAA e Programa Nacional de Fortalecimento da Agricultura Familiar - PNAE) de Alegre-ES. Foram incluídos na pesquisa quinze alimentos: abóbora, agrião, alface, almeirão, banana prata, cebolinha, chuchu, couve, inhame, jiló, mandioca, palmito, quiabo, taioba e tomate. O custo operacional de produção e comercialização, a renda líquida operacional e o índice benefício/custo operacional foram os indicadores econômicos considerados. Verificou-se que alface, banana prata, cebolinha, couve e tomate foram os alimentos que apresentaram renda líquida operacional total positiva nos três mercados enfocados, sendo que os maiores índices benefício/custo foram alcançados pela cebolinha, no PNAE, e pela couve, no PAA. No extremo oposto ficaram a abóbora e o almeirão. A inserção dos agricultores familiares no PNAE foi, na maioria das vezes, a mais vantajosa, ao contrário do PAA, visto que oito dos quinze alimentos enfocados tiveram situação de inviabilidade econômica no mesmo.

Palavras-chave: agricultura familiar, avaliação econômica, mercados alternativos.

\footnotetext{
${ }^{1}$ Graduado em Agronomia (UFES). Analista trade rural. E-mail: caio.biancardi@hotmail.com.

${ }^{2}$ Graduado em Agronomia (UFES). Professor da Escola Família Agrícola de Marilândia-ES. E-mail: rafaeleafcol@hotmail.com.

${ }^{3}$ Graduado em Agronomia (UFES). Mestrado em Extensão Rural (UFV). Doutorado em Produção Vegetal/Socioeconomia (UENF). Professor da Universidade Federal do Espírito Santo (UFES). E-mail: haloysio.siqueira@ufes.br.

${ }^{4}$ Graduada em Agronomia e Engenharia Florestal (UFV). Especialização em Agroecologia (IFES). Mestrado em Solos e Nutrição de Plantas (UFV). Doutoranda em Ciência do Solo (UFLA). Agente de extensão do Instituto Capixaba de Pesquisa, Assistência Técnica e Extensão Rural (INCAPER). E-mail: joana.carneiro@incaper.es.gov.br.

${ }^{5}$ Graduada em Agronomia (UFES). Especialização em Agroecologia (IFES). Profissional autônoma. E-mail: m_aparecidafernandes@hotmail.com.
} 


\title{
ECONOMIC VIABILITY OF FOOD FAMILY PRODUCTION FOR THE INSTITUTIONAL MARKETS OF ALEGRE, ESPÍRITO SANTO STATE, BRAZIL
}

\begin{abstract}
This paper presents and discusses the results of the economic viability analysis of food family production, inserted at the farmer's market and at the institutional markets (Food Acquisition Program - PAA and National School Feeding Program PNAE) of Alegre, Espírito Santo State, Brazil. Fifteen foods were included on the research: pumpkin, watercress, lettuce, wild chicory, banana prata, green onion, chayote, collard greens, yam, scarlet eggplant, cassava, heart of palm, okra, tannia and tomato. The operational cost of production and trading, the operational liquid revenue and the index of benefit/operational cost were the economic indicators considered. It was verified that lettuce, banana prata, green onion, collard greens and tomato were the foods which presented positive value of operational total liquid revenue in the three focused markets, and the higher indexes of benefit/cost were achieved by green onion, in PNAE, and collard greens, in PAA. At the opposite extreme were pumpkin and wild chicory. The insertion of family farmers in PNAE was, most times, the most advantageous, unlike PAA, in which eight of the fifteen focused foods had a situation of economic inviability.
\end{abstract}

Keywords: alternative markets, economic evaluation, family agriculture.

\section{INTRODUÇÃO}

A agricultura familiar vem assumindo posição de destaque na sociedade brasileira, nos últimos vinte anos, em função do apoio recebido através dos programas governamentais, como o Programa Nacional de Fortalecimento da Agricultura Familiar - $\mathrm{PRONAF}^{6}$, o Programa de Aquisição de Alimentos - $\mathrm{PAA}^{7}$ e 0 Programa Nacional de Alimentação Escolar - $\mathrm{PNAE}^{7}$, através dos estudos acadêmicos que deram maior visibilidade de sua importância e também pela conscientização da população quanto aos perigos dos agrotóxicos, cujo uso está mais associado à agricultura patronal. Dessa forma, a agricultura familiar vem sendo encarada, cada vez mais, como importante alternativa para o desenvolvimento rural sustentável, visto que, mesmo cultivando uma área bem menor $(24,3 \%$ do total da área agrícola) que o modelo patronal, contribui muito com a segurança alimentar nacional e a geração de trabalho e renda no campo. França, Del Grossi e Marques (2009), com base no Censo Agropecuário 2006, informam que de cada dez pessoas ocupadas no campo, sete estavam trabalhando na agricultura familiar, a qual gerava $\mathrm{R} \$ 677,00 / \mathrm{ha} / \mathrm{ano}$, contra $\mathrm{R} \$ 358,00 / \mathrm{ha} / \mathrm{ano}$ no modelo patronal, e produzia a maior parte dos alimentos básicos consumidos pelos brasileiros.

Entretanto, os agricultores familiares, em geral, não costumam realizar o controle contábil de sua produção, o que dificulta a verificação da viabilidade econômica da mesma. Inclusive, quando chegam a fazer alguma estimativa rudimentar do custo de produção, a viabilidade é mascarada, muitas vezes, pelo fato deles não contabilizarem a sua própria força de trabalho como parte do custo.

\footnotetext{
${ }_{7}^{6}$ Programa instituído pelo Decreto Federal oㅜ 1.946, de 28 de junho de 1996.

${ }^{7}$ Esses programas serão descritos em tópico a seguir.
} 
O conhecimento dos custos de produção é ainda mais necessário no caso dos agricultores familiares inseridos nos mercados institucionais, como o PAA e o PNAE, pois os preços praticados, que são previamente fixados para vigência durante os contratos firmados com o poder público, nem sempre cobrem os custos de produção.

No município de Alegre-ES, estão em operação os programas governamentais PAA, desde 2007, e PNAE, desde 2010. No caso do PAA, opera-se na modalidade da compra direta dos agricultores, por meio da CONAB, para a doação simultânea a entidades assistenciais (ex.: hospital público e abrigos de crianças desamparadas). Em 2013, existiam 62 agricultores familiares de Alegre participando desse programa, vinculados a seis associações. No caso do PNAE, as aquisições da agricultura familiar para atender à alimentação escolar, em 2013, se limitaram a $15,5 \%$ do total de recursos repassados ao município pelo Fundo Nacional de Desenvolvimento da Educação - FNDE $^{8}$. Mas, em 2015, as aquisições alcançaram o nível de $100,8 \%$ do repasse/FNDE, contando com 39 agricultores participantes, vinculados a nove associações e dois grupos informais.

Diante desse contexto, foi realizada uma pesquisa ${ }^{9}$ sobre os custos de produção e comercialização dos alimentos vendidos pelos agricultores familiares, na feira livre e nos mercados institucionais (PAA e PNAE) de Alegre-ES, tendo em vista a análise de viabilidade econômica dos seus sistemas de produção, inseridos nesses mercados. Por meio do presente artigo, pretende-se apresentar e discutir os resultados dessa avaliação econômica, buscando contribuir para o debate sobre os preços justos que deveriam ser pagos aos agricultores familiares nos mercados institucionais.

\section{AGRICULTURA FAMILIAR E ACESSO A MERCADOS}

A expressão "agricultura familiar", para se referir a uma categoria socioeconômica diferenciada no meio rural, se tornou mais usual nas ciências agrárias a partir dos anos 1990. Uma das definições que melhor traduz o seu sentido considera agricultura familiar como "[...] aquela em que a família, ao mesmo tempo em que é proprietária dos meios de produção, assume o trabalho no estabelecimento produtivo [...]" (WANDERLEY, 2001, p. 23). A família apresenta um vínculo não apenas econômico com a terra, produzindo para garantir, primeiramente, a sua própria segurança alimentar.

Para efeito das políticas públicas, que são enfocadas neste artigo, o agricultor familiar ou empreendedor familiar rural é definido de acordo com a Lei Federal $n^{\circ} 11.326 / 2006$, em seu artigo $3^{\circ}$, de modo que atenda, simultaneamente, aos seguintes requisitos:

I - não detenha, a qualquer título, área maior do que 4 (quatro) módulos fiscais ${ }^{10}$;

II - utilize predominantemente mão-de-obra da própria família nas atividades econômicas do seu estabelecimento ou empreendimento;

\footnotetext{
8 Foram repassados $\mathrm{R} \$ 405.820,00$, conforme informação do FNDE (disponível em: http://www.fnde.gov.br/programas/alimentacao-escolar/alimentacao-escolar-consultas/repasses-financeiros, acesso em: 25 set. 2015).

${ }_{9}^{9}$ Contou com o apoio financeiro da Fundação de Amparo à Pesquisa do Espírito Santo - FAPES.

${ }^{10}$ Cabe esclarecer que o valor do módulo fiscal varia de acordo com o município considerado. Por exemplo, em Alegre-ES o módulo fiscal vale 24 ha, o que define um limite de área de 96 ha para o estabelecimento familiar.
} 
III - tenha percentual mínimo da renda familiar originada de atividades econômicas do seu estabelecimento ou empreendimento, na forma definida pelo Poder Executivo;

IV - dirija seu estabelecimento ou empreendimento com sua família (BRASIL, 2006).

Vários autores já abordaram a questão do acesso a mercados como um dos fatores que afetam a sustentabilidade dos agricultores familiares. Maluf (2004), por exemplo, argumenta que o maior peso relativo do mercado interno brasileiro e a grande diversidade regional podem ampliar as oportunidades para os pequenos e médios empreendimentos agroalimentares, contribuindo muito para a geração de emprego e renda.

Segundo Maluf (2004), a agricultura familiar mantém dois tipos de vínculos com os mercados, que podem ser simultâneos, a saber: a) com cadeias integradas nacional e internacionalmente, englobando as cooperativas de grande porte, as corporações agroindustriais, a indústria alimentar, os agentes de intermediação mercantil e as redes de supermercados; b) com circuitos regionais de produção, distribuição e consumo de alimentos.

Referindo-se à origem e ao desenvolvimento dos circuitos regionais, Maluf (2004, p. 308) afirma que,

[...] A proximidade física não é suficiente para gerar relações sistemáticas e sinérgicas entre os agentes econômicos instalados numa determinada região, relações que constituem condição para a conformação dos referidos circuitos regionais. Essas relações são construídas por processos que refletem as formas sociais de ocupação do território, as opções de estratégia dos agentes econômicos envolvidos e as ações públicas voltadas para promover as atividades econômicas locais e regionais.

Maluf (2004) defende que por meio dos circuitos regionais configura-se um padrão de desenvolvimento socioeconômico mais equitativo. $E$ sugere a implementação de ações públicas visando promover a produção diversificada e o consumo de alimentos regionais de qualidade, incluindo iniciativas autônomas (por parte dos agricultores) de agregação de valor ao produto primário, em forma individual ou associativa. Além disso, seria preciso instituir programas de apoio ao varejo de pequeno porte (como armazéns, quitandas e lojas especializadas), aproximando-o dos agricultores familiares da região.

Outra tipificação dos mercados para os agricultores familiares foi concebida por Wilkinson (2008), identificando quatro formas tradicionais de acesso: o acesso direto (sobressaindo o mercado local/informal), o acesso via atravessador, a integração com as agroindústrias e o acesso por meio das compras do poder público. Esse autor também faz a distinção entre o mercado de commodities, onde as relações são impessoais e mediadas apenas pelo preço, e o que chama de "novos mercados", caracterizados por diferentes processos de fidelização com base na identidade específica dos produtos e processos produtivos. Esses novos mercados englobam as especialidades de nicho, os orgânicos, os artesanais, os solidários e os institucionais.

Segundo Darolt (2013), no Brasil os agricultores familiares têm participação majoritária em circuitos curtos de comercialização (mercados locais). Com base em Chaffotte e Chiffoleau (2007) e Mundler (2008), Darolt distingue dois casos de circuito curto, referentes a produtos agrícolas ou agroindustriais, a saber: a venda 
direta, quando a relação entre produtor e consumidor é direta, na propriedade ou fora dela (em feiras, venda domiciliar, programas governamentais etc.), e a venda por meio de um único intermediário, que pode ser outro produtor, uma cooperativa, uma loja especializada (ex.: produtos agroecológicos), um restaurante ou até um pequeno supermercado.

Para Darolt (2013), os circuitos curtos de comercialização são mais vantajosos, quando comparados aos circuitos longos, porque possibilitam: diversificar as propriedades, reduzindo os riscos; definir preços que remuneram melhor o produtor e são mais justos ao consumidor, pois reforçam a ligação direta entre esses agentes; ofertar alimentos da estação e da região; ampliar a autonomia dos agricultores familiares; dinamizar a economia local, ajudando na manutenção da agricultura familiar; reduzir o impacto ambiental, com menor uso de embalagens plásticas e menor gasto energético com transporte, entre outras vantagens.

Por sua vez, Ploeg (2008) argumenta que foi criado um novo regime alimentar, denominado "imperial", que vem afetando profundamente a estrutura da produção agrícola e agroindustrial, a qualidade dos alimentos e as formas de distribuição dos mesmos. Nesse regime, o mercado global é definido como princípio ordenador, alinhado com os processos globais de acumulação e mediante novas formas de regulação, de modo que se abriram novos espaços para as grandes corporações atuarem como redes coercitivas dentro dos mesmos.

$\mathrm{Na}$ base desse novo regime, de acordo com Ploeg (2008), estão os processos de industrialização da agricultura e de reestruturação das grandes indústrias de processamento, empresas de comercialização e redes de supermercados, constituindo os impérios alimentares, os quais passaram a exercer um crescente poder monopólico e centralizador sobre a produção, a distribuição e o consumo de alimentos. Assim, vem aumentando a desconexão entre os produtores e os consumidores, no tempo e no espaço, e os alimentos são cada vez mais artificializados.

Ploeg (2008) informa que essa nova força opressora dos agricultores familiares (que ele denomina "camponeses") tem causado o rebaixamento dos preços recebidos por eles, ampliando muito a diferença entre os preços oferecidos pela produção primária (matéria-prima) e os preços pagos pelos consumidores, além de elevar os níveis de turbulência mercadológica, não só no mercado alimentar global, como também nos mercados nacionais e regionais que estão interconectados.

Contudo, frente ao regime alimentar imperial, esse autor salienta as iniciativas de resistência dos agricultores familiares, como parte do processo designado "recampesinação", pelo qual são ampliadas as condições de reprodução social dos agricultores familiares (ou camponeses), sobretudo por lhes assegurar maior autonomia. Uma das estratégias de resistência vincula-se ao chamado "capital cultural" desses agricultores que está relacionado, de um lado, à origem, às formas de produção e à qualidade dos alimentos produzidos. De outro lado, o capital cultural.

[...] implica a emergência de circuitos que ligam produtores específicos e lugares de produção específicos a consumidores específicos. Nesses circuitos, as definições culturais de qualidade (e de justiça e sustentabilidade) são um aspecto decisivo. As transações de alimentos ocorrem em circuitos socialmente regulados (e, por isso, também diferenciados) [...] (PLOEG, 2008, p. 305) 
Portanto, nesses circuitos de comercialização, legitimados pelo capital cultural dos agentes envolvidos, ocorreriam relações comerciais mais justas, contribuindo para ampliar a sustentabilidade dos agricultores familiares, com menor dependência do Estado e dos capitais financeiro, industrial e comercial.

Por fim, vale resgatar o Documento Final da I Conferência Nacional de Desenvolvimento Rural Sustentável e Solidário, realizada em 2008, em Olinda-PE, que apresenta as seguintes recomendações relacionadas aos mercados para a agricultura familiar:

\begin{abstract}
Buscar e assegurar novos mercados para os produtos da agricultura familiar e camponesa, povos indígenas e comunidades tradicionais, bem como construir novas estratégias de acesso aos mercados já existentes. O abastecimento do mercado interno pelo cooperativismo solidário, preferencialmente de base agroecológica, representa uma forma de promoção destes produtos e de fortalecimento dos circuitos locais e regionais de comercialização. Destaca-se, ainda, o papel dos mercados institucionais (escolas, creches, instituições da terceira idade, hospitais, restaurantes populares, presídios etc.) que desempenham um importante papel neste processo, especialmente por meio do PAA, que deve ser reforçado em volume de recursos e ter seu acesso desburocratizado, priorizando a operacionalização direta com cooperativas e associações da agricultura familiar e camponesa (BRASIL, 2008, p. 78).
\end{abstract}

\title{
3. OS PROGRAMAS GOVERNAMENTAIS PAA E PNAE
}

O Programa de Aquisição de Alimentos - PAA foi lançado em 2003, através da Lei Federal no 10.696/2003 (art.19), como uma nova estratégia do Governo Federal para enfrentar a questão da fome e da pobreza no Brasil, buscando também fortalecer a agricultura familiar. No PAA, são utilizados mecanismos de comercialização para a aquisição direta de alimentos produzidos por agricultores familiares, assentados da reforma agrária, comunidades indígenas e demais comunidades tradicionais, os quais participam por meio de suas organizações. A compra pode ser feita sem licitação e os preços não devem ultrapassar os valores praticados nos mercados locais.

O PAA é operacionalizado por meio de cinco modalidades ${ }^{11}$, a saber: a) "Compra Direta da Agricultura Familiar para Doação Simultânea", pela qual os alimentos são doados a entidades da rede socioassistencial, restaurantes populares, cozinhas comunitárias e para compor cestas de alimentos distribuídas pelo Governo Federal; b) "Formação de Estoques pela Agricultura Familiar", para que organizações dos agricultores comprem a produção dos seus sócios, formando estoques para posterior comercialização, em momento mais favorável de mercado; c) "Compra Direta da Agricultura Familiar", voltada para situações em que os preços de mercado estão baixos ou para atender às demandas de alimentos para populações em estado de insegurança alimentar; d) "Incentivo à Produção de Leite", que possibilita a distribuição gratuita de leite em ações de combate à fome, nos

\footnotetext{
${ }^{11}$ Para mais detalhes, consultar o site da Secretaria Especial de Agricultura Familiar e Desenvolvimento Agrário, da Casa Civil, disponível em: http://www.mda.gov.br/sitemda/secretaria/saf-paa/modalidades-dopaa.
} 
estados do Nordeste; e) "Compra Institucional". Cada agente produtor pode acessar até um limite anual em cada modalidade.

A modalidade denominada "Compra Institucional" foi criada em 2012, conforme o Decreto no 7.775/2012 e a Resolução no 50/2012. Por meio dessa modalidade, os órgãos de administração direta ou indireta das esferas federal, estadual ou municipal podem comprar alimentos, com seus próprios recursos, dos agentes produtores antes referidos, além de extrativistas e pescadores artesanais, para abastecer restaurantes universitários, unidades do sistema de saúde, presídios, academias de polícia e as forças armadas, entre outros. E a partir de 2015, pelo Decreto $n^{\circ}$ 8.473/2015, estabeleceu-se que os referidos órgãos da esfera federal devem utilizar no mínimo $30 \%$ do total de seus recursos, destinados à aquisição de alimentos, com esse tipo de compra direta.

O Grupo Gestor do PAA é interministerial, sendo coordenado pelo Ministério do Desenvolvimento Social e Combate à Fome. A operacionalização do PAA é de responsabilidade desse Ministério, da CONAB e dos órgãos de administração direta ou indireta. O controle social deve ser exercido pelo Conselho Municipal de Segurança Alimentar e Nutricional ou, na inexistência desse, pelo Conselho Municipal de Ação Social.

Grisa et al. (2011) destacam a relevância do PAA em função das seguintes contribuições: a) alteração na matriz produtiva da agricultura familiar, incentivando a diversificação produtiva e a produção em bases agroecológicas ou orgânicas; b) alteração no consumo das famílias produtoras e das beneficiadas com os alimentos adquiridos pelo governo federal, proporcionando uma alimentação mais diversificada e de melhor qualidade; c) reconexão entre os produtores e os consumidores locais, "[...] respeitando a sazonalidade, a proximidade, os atributos de qualidade, o saberfazer local, as relações sociais, etc." (GRISA et al., 2011, p. 37); d) criação de novos mercados e alternativas de renda aos agricultores familiares, oferecendo uma garantia de comercialização que reduz a sua dependência dos atravessadores; e) promoção do capital social e fortalecimento das organizações dos agricultores familiares.

O Programa Nacional de Alimentação Escolar - PNAE foi criado em 1955, mas, somente a partir de 1994 passou a ocorrer a descentralização do processo de aquisição de alimentos para merenda escolar na rede pública da educação básica, com repasses de recursos aos estados e municípios.

Em 2009, o PNAE passou por outra grande mudança. A Lei Federal no 11.947 estabeleceu que no mínimo $30 \%$ dos recursos financeiros repassados pelo FNDE (Fundo Nacional de Desenvolvimento da Educação) para custear a alimentação escolar, às Secretarias Municipais e Estaduais de Educação, devem ser destinados à aquisição de alimentos oriundos da agricultura familiar ou dos empreendimentos familiares rurais, priorizando-se os assentamentos da reforma agrária, as comunidades tradicionais indígenas e comunidades quilombolas.

A Resolução no 26/2013 do FNDE define as normas para a execução do PNAE e a transferência de recursos financeiros federais. A aquisição poderá ser realizada dispensando-se o procedimento licitatório, com o recurso da "chamada pública". Deve-se priorizar, sempre que possível, os alimentos orgânicos e/ou agroecológicos. O controle social deve ser exercido pelos Conselhos de Alimentação Escolar. E os Institutos Federais (ensino médio/técnico) também podem executar o PNAE.

Para terem direito de acesso aos programas PAA e PNAE, os produtores familiares, extrativistas e pescadores artesanais devem ter essa qualificação comprovada por meio da Declaração de Aptidão ao Pronaf (DAP). E as associações 
ou cooperativas devem possuir DAP-Jurídica, comprovando a predominância desses agentes em seus quadros sociais.

Os programas PAA e PNAE fazem parte da Política Nacional de Segurança Alimentar e Nutricional e estão inseridos no primeiro Plano Nacional de Segurança Alimentar e Nutricional - 2012/2015, relacionando-se aos temas "aquisição de alimentos da agricultura familiar, povos e comunidades tradicionais" e "oferta de alimentos a estudantes, trabalhadores e pessoas em vulnerabilidade alimentar" (CAISAN, 2011).

De acordo com Leão e Maluf (2012, p. 49),

o enfoque da segurança alimentar e nutricional busca ampliar o acesso aos alimentos, ao mesmo tempo em que questiona o padrão inadequado de consumo alimentar, sugere formas mais equitativas, saudáveis e sustentáveis de produzir e comercializar os alimentos e requalifica as ações dirigidas para os grupos populacionais vulneráveis ou com requisitos alimentares específicos. Essas três linhas de ação convertem a busca da segurança alimentar e nutricional num parâmetro para as estratégias de desenvolvimento de um país, como também o são o desenvolvimento sustentável e a equidade social.

\section{METODOLOGIA}

A pesquisa foi conduzida no município de Alegre, situado no Território da Cidadania do Caparaó Capixaba, Estado do Espírito Santo, graças à disponibilização da base de dados de custo de produção e comercialização dos alimentos vendidos pelos agricultores familiares na feira livre e nos mercados do PAA e do PNAE, o que permitiu proceder à avaliação da viabilidade econômica dos seus sistemas produtivos no contexto de tais mercados.

$\mathrm{Na}$ pesquisa, foram abordados, por meio de entrevistas, todos os agricultores familiares que tinham em comum, no ano de 2012, o fato de estarem inseridos em pelo menos dois dos três mercados considerados (feira, PAA e PNAE), o que torna a mesma uma modalidade de censo. E foram incluídos na pesquisa 15 (quinze) alimentos, a saber: abóbora, agrião, alface, almeirão, banana prata, cebolinha, chuchu, couve, inhame, jiló, mandioca, palmito, quiabo, taioba e tomate.

Quando havia mais de um produtor envolvido com o mesmo alimento, contabilizou-se o valor médio de cada item de custo informado da produção respectiva. Os dados referentes aos alimentos produzidos em sistemas de transição agroecológica também foram analisados separadamente.

Para efeito da análise de custo, foram considerados os custos operacionais (total e efetivo) de produção e comercialização, conforme proposto por Matsunaga et al. (1976). Para o custo operacional total, são contabilizados, como custos fixos, os gastos com trabalho permanente (incluindo o familiar), depreciação e impostos, bem como os custos variáveis, englobando os gastos com aquisição do capital circulante, manutenção/conservação do capital estável e o trabalho temporário (contratado). Já no cálculo do custo operacional efetivo, somente são considerados os recursos produtivos que exigem desembolsos por parte do produtor para sua utilização (custos diretos), o que exclui o valor da força de trabalho familiar. Calcularam-se os custos operacionais de produção e comercialização com o auxílio de planilhas do programa Microsoft Excel.

No cálculo dos gastos com o trabalho familiar, apurou-se, com base nas informações do agricultor, todos os dias de serviço dedicados às diferentes frentes 
de trabalho familiar, necessárias para produção e comercialização do alimento enfocado, convertendo os mesmos em equivalentes de diárias de pagamento do trabalho temporário contratado. Ou seja, o valor de cada dia de serviço familiar foi estimado como equivalente ao do trabalhador contratado temporariamente (diarista), conforme valor praticado na região.

Muitas vezes, a família agricultora não realiza o controle contábil de sua produção, principalmente pela característica de sobreposição do orçamento produtivo ao doméstico na rotina da agricultura familiar, o que dificulta a verificação da viabilidade econômica da atividade produtiva. Por isso, foi preciso um esforço meticuloso, durante as entrevistas com os agricultores, para obtenção da estimativa do trabalho gasto especificamente na cultura enfocada, procurando separá-lo do tempo dedicado às demais culturas agrícolas e aos afazeres domésticos.

Os indicadores de rentabilidade considerados foram a renda líquida operacional e o índice benefício/custo operacional. A renda líquida corresponde à diferença entre a receita bruta e o custo operacional. $O$ índice benefício/custo é obtido dividindo-se a receita bruta pelo custo operacional.

Para analisar a rentabilidade, consideraram-se os preços médios recebidos pelos agricultores nos três mercados referidos, ao longo do ano de 2013, corrigidos pelo IGP-DI para o mês de dezembro de 2013. Assim, configuraram-se três cenários econômicos alternativos para os agricultores familiares.

Os preços praticados no PAA refletem o mercado atacadista da CEASA da Grande Vitória, correspondendo à média dos preços nos últimos doze meses antecedentes ao início do contrato do agricultor com a CONAB. Para efeito deste artigo, considerou-se o período de janeiro a dezembro de 2013. Já os preços praticados no PNAE refletem o mercado varejista, correspondendo à média dos preços de três mercados locais, inclusive a feira livre, no ano de 2013.

\section{RESULTADOS E DISCUSSÃO}

Na tabela 1, são apresentados os valores dos custos operacionais unitários de produção e comercialização, totais e efetivos (COT e COE), e os preços recebidos nos diferentes mercados enfocados (PAA, PNAE e feira), para cada alimento estudado.

Tabela 1 - Custos operacionais da produção e comercialização familiar de alimentos e preços recebidos em diferentes mercados de Alegre-ES, 2013.

\begin{tabular}{|c|c|c|c|c|c|}
\hline \multirow[b]{2}{*}{ Alimento } & \multicolumn{2}{|c|}{ Custo operacional $(\mathrm{R} \$ / \mathrm{kg})$} & \multicolumn{3}{|c|}{ Preço recebido $(\mathrm{R} \$ / \mathrm{kg})$} \\
\hline & Total & Efetivo & PAA $^{* *}$ & PNAE $^{\star \star \star}$ & Feira $^{\star \star \star \star}$ \\
\hline Abóbora & 2,22 & 0,05 & 1,05 & 1,53 & 1,55 \\
\hline Agrião & 2,42 & 0,22 & 2,18 & 3,46 & 3,43 \\
\hline Alface & 0,68 & 0,14 & 1,60 & 1,70 & 1,92 \\
\hline Almeirão & 3,87 & 0,44 & 0,81 & 2,17 & 1,72 \\
\hline Banana prata & 1,10 & 0,15 & 1,36 & 1,86 & 1,72 \\
\hline Cebolinha & 1,53 & 0,20 & 2,58 & 6,50 & 6,50 \\
\hline Chuchu & 0,65 & 0,05 & 0,60 & 0,79 & 0,93 \\
\hline Couve & 0,76 & 0,21 & 1,99 & 2,51 & 2,46 \\
\hline Inhame & 2,77 & 0,59 & 2,33 & 3,97 & 3,77 \\
\hline Jiló & 1,44 & 0,30 & 1,21 & 2,04 & 1,72 \\
\hline Mandioca & 1,06 & 0,21 & 1,06 & 2,01 & 1,72 \\
\hline Palmito/cabeça & 1,71 & 0,73 & 1,29 & & \\
\hline Palmito/benef. ${ }^{*}$ & 6,68 & 1,66 & & 9,61 & 9,61 \\
\hline Quiabo & 2,67 & 0,31 & 2,13 & 3,85 & 3,43 \\
\hline Taioba & 3,08 & 0,13 & 3,30 & 2,55 & 2,57 \\
\hline Tomate & 1,19 & 0,47 & 1.67 & 2,41 & 1,90 \\
\hline
\end{tabular}

${ }^{*}$ Descascado, picado e ensacolado.

**Cotação média na CEASA-GV/ES, de janeiro a dezembro de 2013. 


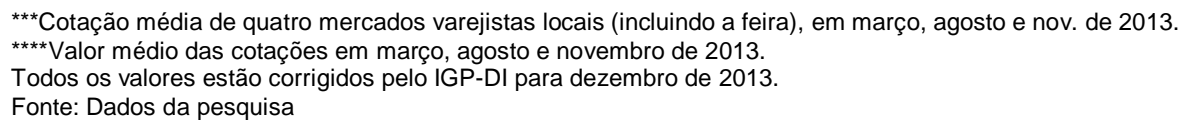

Inicialmente, vale comparar os dados de custo da tabela $1 \mathrm{com}$ os obtidos em outros trabalhos, em valores também corrigidos pelo IGP-DI para o mês de dezembro/2013. Por exemplo, Souza e Garcia (2013), analisando a abóbora, o quiabo e o tomate na região de Domingos Martins-ES, obtiveram os custos unitários (por quilo) de $R \$ 0,72 / \mathrm{kg}, \mathrm{R} \$ 1,48 / \mathrm{kg}$ e $\mathrm{R} \$ 0,79 / \mathrm{kg}$, respectivamente, produzidos em sistema convencional, e os custos de $R \$ 0,60 / \mathrm{kg}, R \$ 1,86 / \mathrm{kg}$ e $R \$ 1,11 / \mathrm{kg}$, em sistema orgânico. Nota-se que quase todos esses valores foram bem inferiores aos de Alegre-ES, exceto o do tomate orgânico, cujo valor ficou próximo. Nos casos da abóbora e do tomate isso se deve às produtividades muito maiores obtidas em Domingos Martins, apesar dos autores não terem contabilizado a depreciação. Quanto ao quiabo, a justificativa seria o maior gasto com a força de trabalho em Alegre.

Cabe ressaltar que os agricultores familiares de Alegre adotaram sistemas produtivos que não correspondem ao sistema convencional e nem tão pouco ao sistema orgânico (tecnicamente conduzido), com exceção do cultivo do tomate que se aproxima mais do sistema orgânico, mas sem certificação. Por isso, foram comparados com os custos de ambos os sistemas de Domingos Martins. Também cabe ponderar que a origem dos dados de Domingos Martins é diferente, pois se refere a condições experimentais (sistema orgânico) ou a coeficientes técnicos médios (sistema convencional), indicados por órgãos ligados à Secretaria Estadual de Agricultura. Em Alegre, os dados refletem a realidade produtiva local, obtidos por meio de entrevistas com os agricultores familiares.

Para comparar com os dados resultantes dos trabalhos citados a seguir, ponderou-se o fato de não terem contabilizado o custo da comercialização. Por isso, foi subtraído esse item dos custos operacionais lançados na tabela 1, antes de proceder à comparação.

A CONAB (2013) informa um custo operacional total (COT) ${ }^{12}$ de $R \$ 0,37 / \mathrm{kg}$ para a banana prata, na região de Alfredo Chaves-ES, e de $R \$ 0,18 / \mathrm{kg}$ para a mandioca de Pinheiros-ES, bem inferiores aos obtidos em Alegre, nos valores de $R \$$ $0,84 / \mathrm{kg}$ e $\mathrm{R} \$ 0,93 / \mathrm{kg}$, respectivamente, pois ambos os dados da CONAB correspondem a situações de produtividade muito maior. No caso do tomate, a diferença entre o COT de Alegre $(\mathrm{R} \$ 0,81 / \mathrm{kg})$ e o encontrado em Domingos Martins$E S(R \$ 0,79 / \mathrm{kg})$ foi pequena, ressaltando que o tomate de Alegre foi produzido sem o uso de agrotóxicos.

Entre os estudos realizados em outros estados brasileiros, identificou-se o de Rezende et al. (2009) que, analisando a alface em cultivo solteiro, na região de Jaboticabal-SP, obtiveram um COT da igual a $R \$ 0,23 / \mathrm{kg}$, enquanto em Alegre foi $\mathrm{R} \$ 0,53 / \mathrm{kg}$. Como não houve diferença significativa de produtividade, essa vantagem econômica da alface de Jaboticabal pode ser explicada devido ao fato de ter sido produzida em condição experimental controlada, ao contrário de Alegre onde os dados refletem a realidade produtiva familiar local, conforme já mencionado.

\footnotetext{
${ }^{12}$ Custos estimados com base numa matriz de coeficientes técnicos e no vetor de preços dos fatores (preços médios praticados em cada região enfocada). Para definição dessa matriz, a CONAB considera o processo produtivo mais utilizado no local, cujos coeficientes técnicos são definidos através de um encontro do qual participam, além dos técnicos da CONAB, produtores rurais e representantes de diversas entidades ligadas à agricultura.
} 
Outro estudo foi realizado por Silva e Chabaribery (2006), que encontraram um COT da mandioca muito mais baixo, para a região de Mogi Mirim-SP, no valor de $R \$ 0,07 / \mathrm{kg}$, frente a $\mathrm{R} \$ 0,76 / \mathrm{kg}$ em Alegre. Igualmente a Alegre, os dados refletem a realidade produtiva local, obtidos por meio de aplicação de questionários com os agricultores. Mas, como não foi contabilizado o custo da colheita, também foi subtraído esse item do COT de Alegre, para essa comparação, além do custo da comercialização. A eficiência técnica em Mogi Mirim foi bem superior, refletindo-se na elevada produtividade que proporcionou um COT unitário quase onze vezes menor. Os autores informam que todos os produtores adotam práticas de conservação de solo e a maioria adota a mecanização e recebe assistência técnica, o que explicaria o enorme contraste de eficiência técnica e econômica entre eles e os produtores capixabas, considerando que ambos têm a predominância do trabalho familiar.

$\mathrm{Na}$ tabela 2, são apresentados os valores dos custos operacionais unitários de produção e comercialização, total e efetivo (COT e COE), referentes aos alimentos produzidos tanto no sistema usual $^{13}$ como no sistema de transição agroecológica $^{14}$.

Tabela 2 - Custos operacionais da produção familiar de alguns alimentos em sistemas usual $(U)$ e de transição agroecológica (T), em Alegre-ES, 2013.

\begin{tabular}{lcc}
\hline Alimento & Custo oper. total $(\mathrm{R} \$ / \mathrm{kg})$ & Custo oper. efetivo $(\mathrm{R} \$ / \mathrm{kg})$ \\
\hline Alface T & 0,16 & 0,04 \\
Alface U & 1,21 & 0,23 \\
Couve T & 1,19 & 0,31 \\
Couve U & 0,34 & 0,12 \\
Banana Prata T-1 & 0,57 & 0,25 \\
Banana Prata T-2 & 1,65 & 0,05 \\
Cebolinha T & 1,53 & 0,16 \\
Cebolinha U & 1,53 & 0,23 \\
\hline
\end{tabular}

Fonte: Dados da pesquisa

Analisando os alimentos mostrados na tabela 2, nota-se, quanto à alface, grande diferença, a menor, nos valores unitários de COT e COE em transição agroecológica. Na alface usual, verificou-se que a baixa produtividade obtida pelo agricultor foi o principal fator que elevou os custos unitários, além do gasto adicional com agroquímicos.

No caso da banana prata, foram abordados dois sistemas de transição agroecológica (T-1 e T-2), sendo o sistema T-1 mais evoluído que o T-2. A adubação inferior e o maior gasto de trabalho na limpeza e manutenção do bananal justificam o maior COT do sistema T-2, visto que o sistema T-1 utiliza técnicas agroflorestais. No entanto, o COE do sistema T-1 foi maior por causa da contratação de força de trabalho (complementar), pois a força de trabalho familiar não é computada nesse custo.

Já para a couve o quadro se inverte, ocorrendo considerável superioridade do sistema usual devido à produtividade bem maior obtida e, provavelmente, ao controle mais eficiente de pragas da couve nesse sistema. No caso da cebolinha,

\footnotetext{
${ }^{13}$ Foi empregada a designação "usual" para fazer referência ao sistema de cultivo adotado pela família que mescla práticas tradicionais (como a capina manual) e práticas consideradas modernas (como a adubação química e o uso de agrotóxicos), embora sem seguir todas as recomendações técnicas.

${ }^{14}$ Conforme Gliessman (2005), refere-se ao processo de conversão de sistemas agrícolas convencionais em agroecológicos, nos quais há diversidade de culturas e a dependência de insumos externos é mínima, entre outras características.
} 
não houve diferença de COT entre os sistemas produtivos enfocados, porém, o COE no sistema usual foi maior porque gastou mais com insumos externos (agroquímicos e esterco). Mesmo sendo o esterco um insumo orgânico, o produtor ficou dependente de comprá-lo, o que não é preconizado na visão agroecológica.

As rendas líquidas operacionais, total e efetiva, obtidas nos mercados de compra direta de alimentos considerados (PAA, PNAE e feira), são apresentadas na tabela 3. 
Tabela 3 - Rendas líquidas operacionais dos agricultores familiares, diante dos diferentes mercados de alimentos de Alegre-ES, 2013.

\begin{tabular}{lrrrrrr}
\hline & \multicolumn{3}{c}{ Renda líq. oper. total $(\mathrm{R} \$ / \mathrm{kg})$} & \multicolumn{3}{c}{ Renda líq. oper. efetiva $(\mathrm{R} \$ / \mathrm{kg})$} \\
\cline { 2 - 7 } Alimento & PAA & PNAE & Feira & PAA & PNAE & Feira \\
\hline Abóbora & $-1,17$ & $-0,69$ & $-0,67$ & 1,00 & 1,48 & 1,50 \\
Agrião & $-0,24$ & 1,04 & 1,01 & 1,96 & 3,24 & 3,21 \\
Alface & 0,92 & 1,02 & 1,24 & 1,46 & 1,56 & 1,78 \\
Almeirão & $-3,06$ & $-1,70$ & $-2,15$ & 0,37 & 1,73 & 1,28 \\
Banana prata & 0,26 & 0,76 & 0,62 & 1,21 & 1,71 & 1,57 \\
Cebolinha & 1,05 & 4,97 & 4,97 & 2,38 & 6,30 & 6,30 \\
Chuchu & $-0,05$ & 0,14 & 0,28 & 0,55 & 0,74 & 0,88 \\
Couve & 1,23 & 1,75 & 1,70 & 1,78 & 2,30 & 2,25 \\
Inhame & $-0,44$ & 1,20 & 1,00 & 1,74 & 3,38 & 3,18 \\
Jiló & $-0,23$ & 0,60 & 0,28 & 0,91 & 1,74 & 1,42 \\
Mandioca & 0,00 & 0,95 & 0,66 & 0,85 & 1,80 & 1,51 \\
Palmito/cab. & $-0,42$ & & & 0,56 & & \\
Palmito/benef. & & 2,93 & 2,93 & & 7,95 & 7,95 \\
Quiabo & $-0,54$ & 1,18 & 0,76 & 1,82 & 3,54 & 3,12 \\
Taioba & 0,22 & $-0,53$ & $-0,51$ & 3,17 & 2,42 & 2,44 \\
Tomate & 0,48 & 1,22 & 0,71 & 1,20 & 1,94 & 1,43 \\
\hline Fomyyyyyyyyyy
\end{tabular}

Fonte: Dados da pesquisa

Analisando os dados da tabela 3 , pode-se constatar que alface, banana prata, cebolinha, couve e tomate foram os únicos os alimentos que apresentaram situação positiva, em termos de renda líquida operacional total, nos três mercados pesquisados, sendo que a cebolinha ficou num nível superior. $E$ a inserção do agricultor familiar no mercado do PNAE foi, na maioria das vezes, a mais vantajosa. O contrário acontece com o PAA que se coloca como o mercado menos favorável.

Em contrapartida, abóbora e almeirão são alimentos que necessitam de grande atenção no momento da comercialização, visto que em todos os mercados pesquisados apresentaram renda líquida operacional total negativa, tornando inviável a comercialização. Enquanto a comercialização da taioba somente é viável no PAA, no caso dos alimentos agrião, chuchu, inhame, jiló, palmito (em cabeça) e quiabo, nota-se, contrariamente, que a comercialização dos mesmos é inviável somente no PAA.

Por outro lado, todos os quinze alimentos apresentaram renda líquida operacional efetiva positiva, o que significa que os preços recebidos nos três mercados cobrem os gastos com insumos e serviços contratados, mas não cobrem a depreciação. E vão remunerar a força de trabalho familiar, não contabilizada no custo efetivo, de acordo com o valor da renda efetiva obtida.

A seguir, na figura 1, encontram-se expostos os índices benefício/custo operacional total (IBCs) para cada mercado de alimentos considerado. 
Figura 1 - Índices benefício/custo operacional total, diante dos diferentes mercados de alimentos de Alegre-ES, 2013.

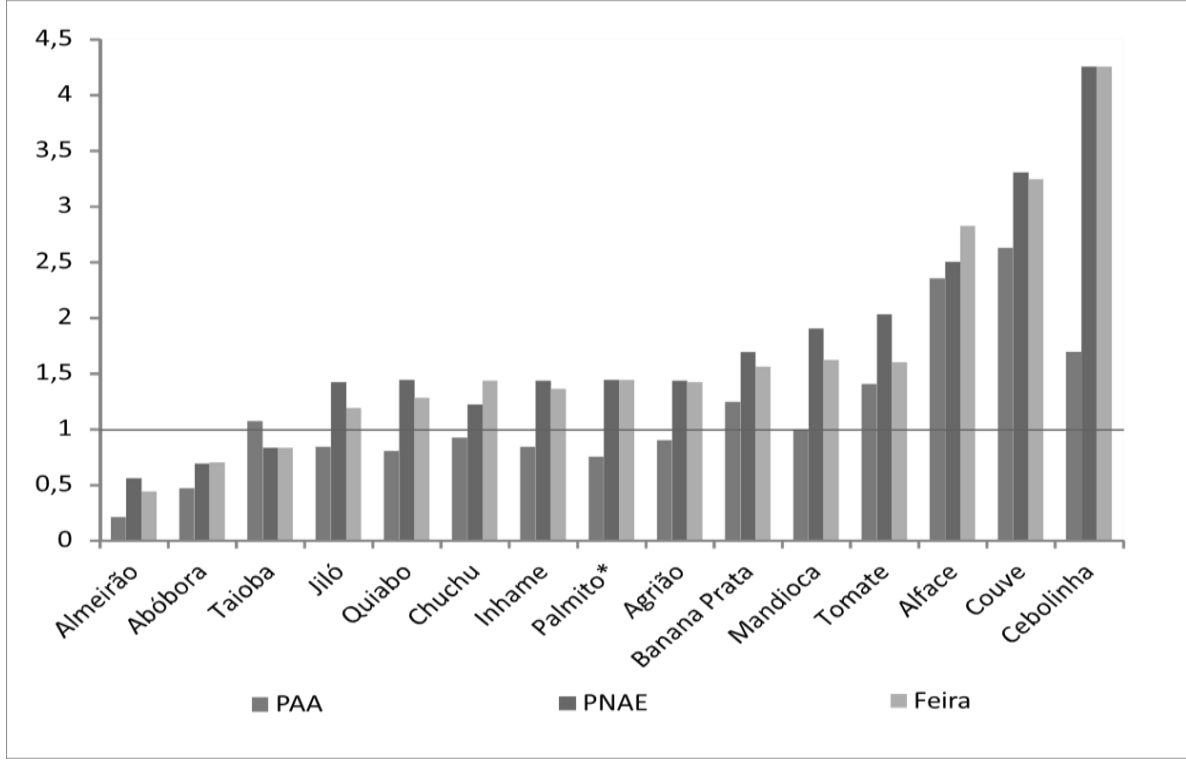

${ }^{*}$ Refere-se ao palmito em cabeça, no caso do PAA, e ao palmito beneficiado, no PNAE e na feira.

Fonte: Dados da pesquisa

Observa-se que alface, cebolinha e couve foram os alimentos que alcançaram os maiores IBCs nos três mercados, com destaque para a cebolinha que chegou ao valor máximo de 4,25 , no PNAE e na feira, o que significa que cada $R \$$ 1,00 investido na produção de cebolinha gerou um retorno de $R \$ 4,25$, ao ser vendida em tais mercados. No extremo oposto estão abóbora e almeirão, que apresentaram IBCs sempre inferiores a uma unidade, indicando que a comercialização dos mesmos é inviável nos três mercados enfocados. Essa situação de inviabilidade econômica $($ IBC $<1,00)$ foi mais comum no PAA, envolvendo oito $(53,3 \%)$ dos quinze alimentos.

Diante desse quadro econômico, torna-se muito relevante a discussão sobre os preços justos que deveriam ser pagos aos agricultores familiares nos mercados institucionais, como o PAA e o PNAE, considerando que um dos critérios para definição desses preços deveria ser a remuneração dos custos de produção e comercialização.

Tais mercados, que representam circuitos curtos de comercialização, podem ser analisados na perspectiva da "comercialização justa e solidária", que se baseia nos princípios da transparência, corresponsabilidade, relação de longo prazo, pagamento de preço justo e respeito ao meio ambiente e à dignidade do trabalho (Fairtrade Labelling Organizations International, 2006). Assim, fica clara a preocupação de garantir um preço justo ao produtor, como uma das condições para estabelecer relações mais solidárias entre quem produz e quem consome alimentos.

Nesse mesmo sentido, autores como Darolt (2013), Wilkinson (2008) e Ploeg (2008) também argumentam que os circuitos curtos possibilitam relações comerciais mais solidárias, onde os preços praticados remuneram melhor o produtor e são mais justos ao consumidor, pois reforçam a ligação direta entre esses agentes. A questão é que nem sempre isso vigora, como foi demonstrado neste 
estudo, apontando a inviabilidade econômica de venda pelo PAA de mais da metade dos alimentos pesquisados, devido ao fato do programa considerar os preços de atacado ${ }^{15}$.

Entretanto, cabe fazer uma ressalva para uma análise mais ponderada da questão dos preços justos. Considerando que a maioria dos alimentos pesquisados em Alegre apresentou valores de custo superiores àqueles obtidos em outras regiões, se coloca o desafio de melhorar a eficiência técnica dos sistemas de produção, para torná-los mais competitivos economicamente.

\section{CONCLUSÕES}

O estudo permitiu constatar que alface, banana prata, cebolinha, couve e tomate foram os únicos alimentos que apresentaram renda líquida operacional total positiva nos três mercados pesquisados, sendo que os maiores índices benefício/custo operacional total foram alcançados pela cebolinha, no PNAE, e pela couve, no PAA. No extremo oposto ficaram a abóbora e o almeirão, cuja renda foi sempre negativa nesses mercados, apresentando índices benefício/custo inferiores a uma unidade.

Por outro lado, todos os quinze alimentos estudados apresentaram renda líquida operacional efetiva positiva, nos três mercados, visto que os preços recebidos cobrem os gastos com insumos e serviços contratados. Porém, não cobrem a depreciação e podem não estar remunerando toda a força de trabalho familiar.

Enquanto a comercialização da taioba somente é viável no PAA, no caso dos alimentos agrião, chuchu, inhame, jiló, palmito (em cabeça) e quiabo, nota-se, contrariamente, que a comercialização dos mesmos é inviável somente no PAA.

A inserção dos agricultores familiares no PNAE foi, na maioria das vezes, a mais vantajosa, ao contrário do PAA. Por isso, é contraditório dizer que o PAA esteja executando modalidades de "compra direta" da agricultura familiar, na medida em que estabelece o mercado atacadista como base de preço, o que rebaixa o preço a ser pago, na maior parte dos casos.

Os resultados de custo operacional de produção e comercialização obtidos possibilitam analisar, frente aos preços vigentes, qual o melhor mercado para venda dos alimentos da agricultura familiar. As planilhas referenciais de custo, elaboradas com base nos quinze sistemas produtivos adotados na região de Alegre, foram disponibilizadas em um blog/internet. Inclusive, poderão ser aplicadas em outras regiões mediante as devidas adaptações às suas especificidades. Desse modo, o agricultor familiar terá uma importante ferramenta para fazer o controle contábil da produção e escolher os alimentos e os mercados mais rentáveis.

Espera-se que este estudo seja útil na negociação dos preços justos para os alimentos comercializados nos mercados institucionais (PAA e PNAE), sabendo que um dos critérios de definição dos preços deveria ser a remuneração dos custos. Tais mercados, mesmo com os problemas verificados, estão contribuindo para proporcionar segurança alimentar e nutricional da população beneficiada e, ao

\footnotetext{
${ }^{15}$ Além dos preços desfavoráveis, os agricultores familiares entrevistados relataram que vêm enfrentando outro enorme obstáculo na comercialização pelo PAA. Refere-se ao descompasso entre o ritmo dos trâmites burocráticos, no âmbito da CONAB, e o ritmo dos ciclos biológico-produtivos das plantas e dos animais. O processo que vai da apresentação da proposta (da associação rural) até a liberação dos recursos financeiros, autorizando a entrega dos alimentos às entidades assistenciais, é muito demorado. Enquanto isso, as frutas e verduras vão passando do ponto de colheita, se perdendo no campo, e os animais vão passando do ponto de abate. Assim, esse programa vem perdendo credibilidade perante os agricultores.
} 
mesmo tempo, estão ampliando as possibilidades de comercialização para a agricultura familiar.

\section{AGRADECIMENTOS}

À Fundação de Amparo à Pesquisa do Espírito Santo - FAPES, pelo apoio financeiro, e aos agricultores familiares entrevistados, pelas informações prestadas.

\section{REFERÊNCIAS}

BRASIL. Ministério do Desenvolvimento Agrário. Relatório final da I Conferência Nacional de Desenvolvimento Rural Sustentável e Solidário. Brasília, 2008.

BRASIL. Lei no. 1.326, de 24 de julho de 2006. Brasília, 2006. Disponível em: <http://www.planalto.gov.br/ccivil_03/_ato2004-2006/2006/lei/l11326.htm>.

Acesso em: 25 abr. 2014.

CAISAN - CÂMARA INTERMINISTERIAL DE SEGURANÇA ALIMENTAR E NUTRICIONAL. Plano nacional de segurança alimentar e nutricional 2012/2015. Brasília: CAISAN, 2011. 132p.

\section{COMPANHIA NACIONAL DE ABASTECIMENTO - CONAB. ES-Custos PGPAF Maio 2013. Brasília, 2013. Disponível em:} <http://www.conab.gov.br/conteudos.php?a=1286\&t=2>. Acesso em: 08 jul. 2013.

DAROLT, M. R. Circuitos curtos de comercialização de alimentos ecológicos: reconectando produtores e consumidores. In: NIEDERLE, P. A.; ALMEIDA, L.; VEZZANI, F. M. (Org.). Agroecologia: práticas, mercados e políticas para uma nova agricultura. Curitiba: Kairós, 2013, p.139-170.

FAIRTRADE LABELLING ORGANIZATIONS INTERNATIONAL. Documento explicativo sobre os critérios gerais de comércio justo para organizações de pequenos produtores. [S.I.], 2006. Disponível em: <www.fairtrade.net/uploads/media/Explan_Doc_Small_Farmers_Mar_2006_PT.pdf>. Acesso em 02 fev. 2009.

FRANÇA, C. G.; DEL GROSSI; M. E.; MARQUES V. P. M. A. O censo agropecuário 2006 e a agricultura familiar no Brasil. Brasília: MDA, 2009.

GLIESSMAN, S. R. Agroecologia: processos ecológicos em agricultura sustentável. 3.ed. Porto Alegre: UFRGS, 2005.

GRISA, C. et al. Contribuições do programa de aquisição de alimentos à segurança alimentar e nutricional e à criação de mercados para a agricultura familiar. Agriculturas: experiências em agroecologia, Rio de Janeiro, v. 8, n. 3, p. 34-41, set. 2011.

LEÃO, M. M.; MALUF, R. S. A construção social de um sistema público de segurança alimentar e nutricional: a experiência brasileira. Brasília: ABRANDH, 2012. 
MALUF, R. S. Mercados agroalimentares e a agricultura familiar no Brasil: agregação de valor, cadeias integradas e circuitos regionais. Ensaios FEE, Porto Alegre, v. 25, n. 1, p. 299-322, abr. 2004.

MATSUNAGA, M. et al. Metodologia de custo de produção utilizada pelo IEA. Agricultura em São Paulo, São Paulo, v. 23, t. 1, p. 123-39, 1976.

PLOEG, J. D. van der. Camponeses e impérios alimentares: lutas por autonomia e sustentabilidade na era da globalização. Porto Alegre: UFRGS, 2008.

REZENDE, B. L. A. et al. Custo de produção e rentabilidade das culturas de alface, rabanete, rúcula e repolho em cultivo solteiro e consorciadas com pimentão. Ciência e Agrotecnologia, Lavras-MG, v.33, n.1, p.305-312, jan./fev., 2009. Disponível em: <http://dx.doi.org/10.1590/S1413-70542009000100042>. Acesso em: 03 mar. 2014.

SILVA, J. R.; CHABARIBERY, D. Coeficientes técnicos e custo de produção da mandioca para mesa na região de Mogi-Mirim, Estado de São Paulo. Informações Econômicas, São Paulo, v. 36, n. 1, p. 26-32, jan. 2006. Disponível em: <ftp://ftp.sp.gov.br/ftpiea/publicacoes/tec3-0106.pdf>. Acesso em: 03 mar. 2014.

SOUZA, J. L.; GARCIA, R. D. C. Custos e rentabilidades na produção de hortaliças orgânicas e convencionais no estado do Espírito Santo. Revista Brasileira de Agropecuária Sustentável, Viçosa-MG, v.3, n.1, p.11-24, jul. 2013. Disponível em: <http://www.rbas.com.br/pdf/revista_5_artigo_108.pdf>. Acesso em: 03 mar. 2014.

WANDERLEY, M. N. B. Raízes históricas do campesinato brasileiro. In: TEDESCO, J. C. (Org.). Agricultura familiar: realidades e perspectivas. Passo Fundo: UPF, 2001. p. 21-55.

WILKINSON, J. Mercados, redes e valores: o novo mundo da agricultura familiar. Porto Alegre: UFRGS, 2008. 